\title{
ANALISA PERBANDINGAN PERENCANAAN OPTIMASI CONTINUOUS GAS LIFT DENGAN SIMULATOR PIPESIM DAN MANUAL SUMUR “A1" DAN “A2" DI LAPANGAN "D”
}

\author{
Aristanti Oktavia Dewi ${ }^{1)}$, Wirawan Widya Mandala ${ }^{2)}$ \\ ${ }^{1,2)}$ Prodi Teknik Perminyakan, Fakultas Teknik, Universitas Proklamasi 45 Yogyakarta \\ Coresponding author. email :aristantioktavia@gmail.com
}

\begin{abstract}
Abstrak
Sumur "A1" dan sumur "A2" adalah sumur yang beroperasi di lapangan "D" dengan metode produksi continuous gas lift. Pada Sumur "A1" telah terpasang instalasi gas lift dengan 7 katup. Sedangkan pada Sumur "A2" telah terpasang 6 katup. Sumber gas untuk injeksi berasal dari satu sumur gas pada lapangan yang sama, dimana sebagian besar produksi gas dijual ke konsumen, dan sebagian untuk injeksi. Sehingga jumlah gas dibatasi $0.7 \mathrm{MMCF} / \mathrm{d}$ untuk injeksi. Kurangnya kemampuan kompresor menyebabkan tekanan untuk injeksi gas dibatasi maksimal 750 psia.Pada Sumur "A1" dengan laju alir gas injeksi sebesar 0,4 MMSCF/d dan tekanan injeksi gas sebesar 550.7 psia pada kondisi sekarang hanya mampu mengaktifkan katup gas lift ke-3 sebagai katup operasi, dari 7 katup yang telah terpasang pada sumur. Laju alir total yang dihasilkan 245 STB/d (WC 84\%). Sedangkan pada Sumur "A2" dengan laju alir gas injeksi sebesar 0,38 MMSCF/d dan tekanan injeksi gas sebesar 550 psia pada kondisi sekarang hanya mampu mengaktifkan katup gas lift ke-3 sebagai katup operasi, dari 6 katup yang telah terpasang pada sumur. Laju alir total yang dihasilkan adalah 61 STB/d (WC 74\%).

Laju alir gas injeksi dan besarnya tekanan injeksi permukaan pada desain existing continuous gas lift Sumur "A1" dan "A2" belum optimum. Oleh karena itu, perlu dilakukan redesign maupun optimasi. Tujuannya agar memperoleh laju alir gas injeksi dan tekanan injeksi permukaan optimum yang memberikan hasil laju alir total terbesar, disesuaikan dengan batasan kondisi lapangan.

Redesign dilakukan menggunakan simulator pipesim dan manual. Kemudian, optimasi produksi dilakukan menggunakan pipesim berdasarkan Metode Jones \& Brown untuk meningkatkan profil produksi kedua sumur.

Pada Sumur "A1", perbandingan redesign dengan pipesim "new spacing" dan manual, hasilnya cenderung sama. Sehingga digunakan "new spacing" yang dinilai lebih teliti dengan titik injeksi pada KSB V (1122.2 m), GLRtotal 2650 SCF/STB, WC 84\%, laju produksi total 324 BFPD (52 BOPD). Optimasi menggunakan Current Spacing diperoleh katup operasi pada KSB IV (1062.23 m) dengan laju produksi total 335.3 BFPD (54 BOPD). Peningkatan fluida yang dihasilkan pada Sumur "A1", yaitu dari 245 BFPD menjadi 324 BFPD dengan kenaikan perolehan minyak dari 39.2 BOPD menjadi 54 BOPD.Pada sumur A2, dilakukan redesign dengan pipesim "new spacing" dengan titik injeksi pada KSB VI (1356.5 m), GLRtotal 5700 SCF/STB, WC 74\%, laju produksi total 126 BFPD (33 BOPD). Sedangkan optimasi menggunakan Current Spacing diperoleh katup operasi pada KSB V $(1365.3 \mathrm{~m})$ dengan laju produksi total 128 BFPD (33 BOPD). Peningkatan fluida yang dihasilkan pada Sumur "A2", yaitu dari 61 BFPD menjadi 128 BFPD dengan kenaikan perolehan minyak dari 15 BOPD menjadi 33 BOPD.

Pada sumur "A1" dan "A2" lebih efektif mengoptimasi produksi berdasarkan current spacing. Karena tidak memerlukan rig untuk mengubah kedalaman katup existing sehingga dapat menghemat biaya, energi, dan waktu. Cukup hanya dengan menambah tekanan injeksi di permukaan dan laju injeksi gasnya, dapat diperoleh produksi yang lebih baik.
\end{abstract}

Kata kunci : Perencanaan Optimasi, Continous Gas Lift, Pipesim

\section{Pendahuluan}

\subsection{Latar Belakang}

Kondisi suatu sumur apabila diproduksikan terus-menerus maka lama kelamaan akan mengakibatkan tekanan reservoir turun sehingga laju alir turun. Hal tersebut mengakibatkan produktivitas sumur akan turun juga. Untuk itu perlu adanya tenaga yang dapat membantu untuk mengangkat fluida sampai ke permukaan. Metode Produksi dibagi menjadi tiga, yaitu Primary Recovery, Secondary Recovery (Pressure Maintenance), dan Tertiary Recovery (Enhanced Oil Recovery). Continuous Gas Lift merupakan salah satu dari metode artificial lift sehingga termasuk dalam Primary Recovery.
Continuous Gas Lift adalah penginjeksian gas secara terus menerus ke dalam annulus dan melalui valve yang dipasang pada tubing, gas masuk ke dalam tubing tersebut. Parameter yang berpengaruh pada pemilihan gas lift antara lain: Productivity Index (PI), Gas Liquid Ratio (GLR), kedalaman sumur dan mekanisme pendorong reservoir. Gas lift banyak dipergunakan karena mempunyai kelebihan dibandingkan dengan metode artificial lift lainnya, seperti biaya peralatan awal yang rendah, pasir yang ikut terproduksi tidak merusak kebanyakan peralatan gas lift, gas lift tidak tergantung dari desain sumur, umur peralatan relatif lebih lama, dan biaya operasi yang relatif kecil. Meskipun 
demikian gas lift mempunyai batasan-batasan, seperti gas harus tersedia, sentralisasi compressor sulit untuk sumur-sumur dengan jarak terlalu jauh, dan gas yang tersedia sangat korosif, kecuali menggunakan gas dehydrated.

\subsection{Maksud dan Tujuan}

Maksud dari penelitian ini adalah untuk menganalisa dan memperoleh laju produksi optimum dengan menggunakan laju alir gas injeksi serta tekanan jaringan injeksi gas optimum dengan metode continuous gas lift dengan menggunakan simulator Pipesim dan secara manual.

Tujuan dari penelitian adalah: menganalisa dan mengetahui permasalahanpermasalahan produksi dengan metode continuous gas lift, mengevaluasi dan mengoptimasi pekerjaan gas lift berdasarkan rate gas injeksinya dan tekanan gas injeksinya dan memperoleh besarnya laju alir gas injeksi dan tekanan injeksi permukaan yang optimum, sehingga menghasilkan laju produksi total tertinggi.

\subsection{Stratigrafi Cekungan Jawa Barat Utara}

Stratigrafi umum Jawa Barat Utara dapat dilihat pada Gambar 1. berturut-turut dari tua ke muda adalah sebagai berikut:

1. Batuan Dasar

Batuan dasar adalah batuan beku andesitik dan basaltik yang berumur Kapur Tengah sampai Kapur Atas dan batuan metamorf yang berumur Pra Tersier (Sinclair, et.al, 1995). Lingkungan pengendapannya merupakan suatu permukaan dengan sisa vegetasi tropis yang lapuk (Koesoemadinata, 1980).

\section{Formasi Jatibarang}

Satuan ini merupakan endapan early synrift, terutama dijumpai di bagian tengah dan timur dari Cekungan Jawa Barat Utara. Pada bagian barat cekungan ini kenampakan Formasi Jatibarang tidak banyak (sangat tipis) dijumpai. Formasi ini terdiri dari tulfa, breksi, aglomerat, dan konglomerat alas. Formasi ini diendapkan pada fasies fluvial. Umur formasi ini adalah dari kala Eosen Akhir sampai Oligosen Awal. Pada beberapa tempat di Formasi ini ditemukan minyak dan gas pada rekahan-rekahan tuff (Budiyani, dkk, 1991).

\section{Formasi Talangakar}

Pada fase synrift berikutnya diendapkan Formasi Talangakar secara tidak selaras di atas Formasi Jatibarang. Pada awalnya berfasies fluvio-deltaic sampai fasies marine. Litologi formasi ini diawali oleh perselingan sedimen batupasir dengan serpih nonmarine dan diakhiri oleh perselingan antara batugamping, serpih, dan batupasir dalam fasies marine. Pada akhir sedimentasi, Formasi Talangakar ditandai dengan berakhirnya sedimentasi synrift. Formasi ini diperkirakan berkembang cukup baik di daerah Sukamandi dan sekitarnya.

Adapun terendapkannya formasi ini terjadi dari Kala Oligosen sampai dengan Miosen Awal.

\section{Formasi Baturaja}

Formasi ini terendapkan secara selaras di atas Formasi Talangakar. Pengendapan Formasi Baturaja yang terdiri dari batugamping, baik yang berupa paparan maupun yang berkembang sebagai reef buildup menandai fase post rift yang secara regional menutupi seluruh sedimen klastik Formasi Talangakar di cekungan Jawa Barat Utara. Perkembangan batugamping terumbu umumnya dijumpai pada daerah tinggian. Namun, sekarang diketahui sebagai daerah dalaman. Formasi ini terbentuk pada kala Miosen Awal-Miosen Tengah (terutama dari asosiaso foraminifera). Lingkungan pembentukan formasi ini adalah pada kondisi laut dangkal, air cukup jernih, sinar matahari ada (terutama dari melimpahnya foraminifera Spriroclypens $S p$ ).

\section{Formasi Cibulakan Atas}

Formasi ini terdiri dari perselingan antara serpih dengan batupasir dan batugamping. Batugamping pada satuan ini umumnya merupakan batugamping klastik serta batugamping terumbu yang berkembang secara setempat-setempat. Batugamping ini dikenali sebagai Mid Main Carbonate (MMC). Formasi ini diendapkan pada kala Miosen Awal-Miosen Akhir. Formasi ini terbagi menjadi 3 anggota, yaitu:

a) Massive

Anggota ini terendapkan secara tidak selaras di atas Formasi Baturaja. Litologi anggota ini adalah perselingan batulempung dengan batupasir yang mempunyai ukuran butir dari halus-sedang. Pada massive ini dijumpai kandungan hidrokarbon, terutama pada bagian atas. Selain itu terdapat fosil foraminifera planktonik, seperti Globigerina tribolus, foraminifera bentonik seperti Amphistegina (Arpandi dan Patmosukismo, 1975). 
b) Main

Anggota Main terendapkan secara selaras diatas Anggota Massive. Litologi penyusunnya adalah batulempung berselingan dengan batupasir yang mempunyai ukuran butir halus-sedang (bersifat glaukonitan). Pada awal pembentukannya berkembang batugamping dan juga blangket-blangket pasir, dimana pada bagian ini Anggota Main terbagi lagi yang disebut dengan Mid Main Carbonat (Budiyani dkk, 1991). c) Pre Parigi

Anggota Pre Parigi terendapkan secara selaras diatas Anggota Main. Litologinya adalah perselingan batugamping, dolomite, batupasir, dan batulanau. Anggota ini terbentuk pada kala Miosen Tengah-Miosen Akhir dan diendapkan pada lingkungan Neritik TengahNeritik Dalam (Arpandi dan Patmosukismo, 1975), dengan dijumpainya fauna-fauna laut dangkal dan juga kandungan batu pasir glaukonitan.



Gambar 1. Stratigrafi Cekungan Jawa Barat Utara 


\section{ANALISA PERBANDINGAN PERENCANAAN OPTIMASI CONTINUOUS GAS LIFT DENGAN SIMULATOR PIPESIM DAN MANUAL SUMUR "A1" DAN "A2" DI LAPANGAN "D"}

\section{Formasi Parigi}

Fomasi ini terendapkan secara selaras di atas Formasi Cibulakan Atas. Litologi penyusunnya sebagian besar adalah batugamping klastik maupun batugamping terumbu. Pengendapan batugamping ini melampar ke seluruh Cekungan Jawa Barat Utara. Lingkungan pengendapan formasi ini adalah laut dangkal - neritik tengah (Arpandi dan Patmosukismo, 1975). Batas bawah Formasi Parigi ditandai dengan perubahan berangsur dari batuan fasies campuran klastik karbonat Formasi Cibulakan Atas menjadi batuan karbonat Formasi Parigi. Formasi ini diendapkan pada kala Miosen Akhir-Pliosen.

\section{Formasi Cisubuh}

Formasi ini terendapka secara selaras di atas Formasi Parigi. Litologi Penyusunnya adalah batu lempung berselingan dengan batupasir dan serpih gampingan. Umur formasi ini adalah dari kala Miosen Akhir sampai Pliosen - Pleistosen. Formasi diendapkan pada lingkungan laut dangkal yang semakin ke atas menjadi lingkungan litoral paralik (Arpandi dan Patmosukismo, 1975).

\section{Metodologi}

Metodologi yang digunakan dalam studi ini adalah optimasi continuous gas lift berdasarkan Metode Jones \& Brown. Jones \& Brown mengemukakan bahwa optimasi continuous gas lift sangat dipengaruhi oleh ukuran tubing, tekanan injeksi gas, volume gas injeksi, desain katup gas lift dan tekanan balik permukaan. Dalam penulisan laporan penelitian ini penulis menggunakan data sumur produksi gas lift yang dan selanjutnya dilakukan redesign menggunakan simulator pipesim dan manual. Kemudian, optimasi produksi dilakukan menggunakan pipesim untuk meningkatkan profil produksi kedua sumur tersebut.

Tahapan dalam penelitia ini adalah :

\section{Studi Literatur}

Merupakan metodologi yang difokuskan pada publikasi ilmiah mengenai teori yang berhubungan dengan analisa dan perencanaan optimasi produksi menggunakan metode continuous gas lift.

2. Pengumpulan dan Penginputan Data kedalam Simulator

Merupakan metodologi observasi dan diskusi. Observasi lapangan bertujuan untuk mengetahui kondisi lapangan, serta diskusi dengan pembimbing lapangan mengenai optimasi continuous gas lift.
3. Validasi model pada simulator, agar laju alir yang dihasilkan sesuai dengan kondisi aktual.

4. Melakukan sensitivitas terhadap laju alir gas injeksi, sehingga diperoleh laju alir gas injeksi optimum.

5. Melakukan redesign continuous gas lift sesuai besarnya laju alir gas injeksi dan tekanan injeksi permukaan optimum serta membandingkan hasilnya menggunakan simulator Pipesim dan secara manual.

6. Memilih metode untuk mengoptimalkan produksi continuous gas lift antara redesign dan optimasi dengan menggunakan simulator pipesim

\section{Hasil dan Pembahasan}

Metode Produksi terdiri dari Metode Primer, Sekunder, dan Tersier. Penulis membahas tentang metode primer khususnya continuous Gas Lift. Gas Lift merupakan cara pengangkatan fluida dari suatu sumur yang berproduksi dengan laju alir rendah atau tidak mampu lagi berproduksi secara alami. Gas diinjeksikan melalui annulus casing-tubing (melalui katup gas Lift) sehingga fluida dalam tubing menjadi lebih ringan, karena densitas lebih rendah, viscositas lebih rendah, perbandingan GLR lebih besar dibandingkan fluida reservoir, dan memperkecil pressure loss sehingga menyebabkan fluida mengalir ke permukaan. Continuous Gas Lift merupakan penginjeksian gas secara terus menerus.

Sumur "A1" diproduksikan dari Formasi Jatibarang pada lapisan $\mathrm{H}$ dimana merupakan reservoir dengan tenaga pendorong solution gas drive. Awalnya, dilakukan evaluasi dengan pipesim menggunakan single branch model. Tahapan evaluasi, yaitu input data (black oil, komplesi, tubing, gas lift existing), running program modeling, validasi model dan desain existing. Input data Sumur "A1" Setelah running program modeling, dihasilkan IPR yang belum sesuai kondisi aktual, maka dilakukan validasi model menggunakan flow correlation matching. Korelasi yang dipilih adalah korelasi Orkiszweski. Laju alir yang dihasilkan dari perpotongan kurva IPR dan TIP sebesar 246 STB/d pada tekanan alir dasar sumur sebesar 1182 psia. Hasil ini yang paling mendekati kondisi actual. Kemudian, dilakukan desain existing continuous gas lift. Hasil evaluasinya, yaitu dengan laju alir gas injeksi 0,4 MMSCF/d dan tekanan injeksi permukaan 550.7 psia hanya mampu mengangkat cairan sampai pada katup ketiga $(847.06 \mathrm{~m})$ dengan laju alirnya sebesar 246 BFPD. Analisis IPR terdapat pada Gambar 2. 




Gambar 2. Tampilan Validasi Model Existing IPR dan TIP Sumur "A1"

Jika dilihat dari desain existing Continuous Gas Lift pada Sumur "A1", laju alir produksinya dapat ditingkatkan dengan menaikkan laju alir gas injeksi dan tekanan injeksi permukaannya berdasarkan kemampuan fasilitas di lapangan (Pso=750 psia dan Qgi=0.7 mmscf/d). Sehingga dilakukan redesign continuous gas lift dengan membandingkan metode simulator pipesim dan manual. Redesign menggunakan pipesim (new spacing) menghasilkan 5 katup yaitu $459.73 \mathrm{~m}$,
745.48, 935.37, 1055.7, 1122.2 m. Sedangkan tekanan buka katupnya, yaitu 666.4 psi, 613.3 psi, 604.3 psi, 610.3 psi, dan KSB V sebagai katup operasi $(1122.2 \mathrm{~m})$ dengan port size 5/16 inch. Laju produksi total sebesar 324 bfpd pada Pwf 1050.7 psia sehingga memperoleh produksi minyak sebesar 51.84 bopd (WC 84\%). Gambar 3 merupakan IPR setelah redesign dengan new spacing.

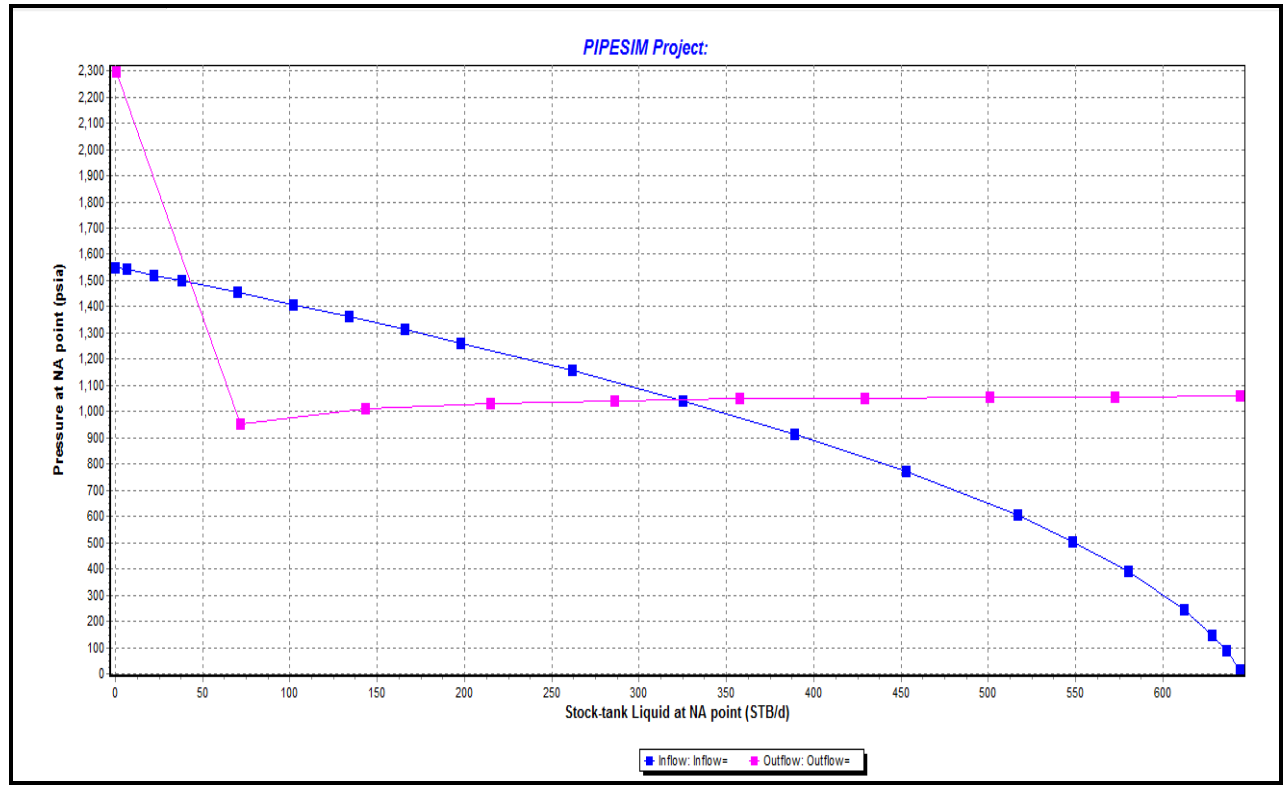

Gambar 3. Tampilan IPR Sumur "A1” Setelah Redesign New Spacing

Hasil redesign manual diperoleh katup $\mathrm{V}$ sebagai katup operasi (1128.05 $\mathrm{m})$ dengan laju produksi total 324 bfpd dan laju produksi minyak 51.84 bopd. Kedalaman katup-katupnya, yaitu $457.17 \mathrm{~m}, 739.10 \mathrm{~m}, 906.76 \mathrm{~m}, 1013.41 \mathrm{~m}, 1127.7$ m. Tekanan buka katup-katupnya, yaitu 698.56 psi,
683.72 psi, 666.29 psi, 686.17 psi. Gambar 4. merupakan IPR Sumur "A1" setelah redesign manual. Berdasarkan perbandingan keduanya, perbedaan terdapat pada kedalaman katup dan tekanan buka katup (Ptro). Desain manual diasumsikan terjadi kesalahan pengamatan. 


\section{ANALISA PERBANDINGAN PERENCANAAN OPTIMASI CONTINUOUS GAS LIFT DENGAN SIMULATOR PIPESIM DAN MANUAL SUMUR "A1" DAN "A2" DI LAPANGAN "D"}

Sehingga, penulis memilih menggunakan Pipesim New Spacing untuk selanjutnya dibandingkan

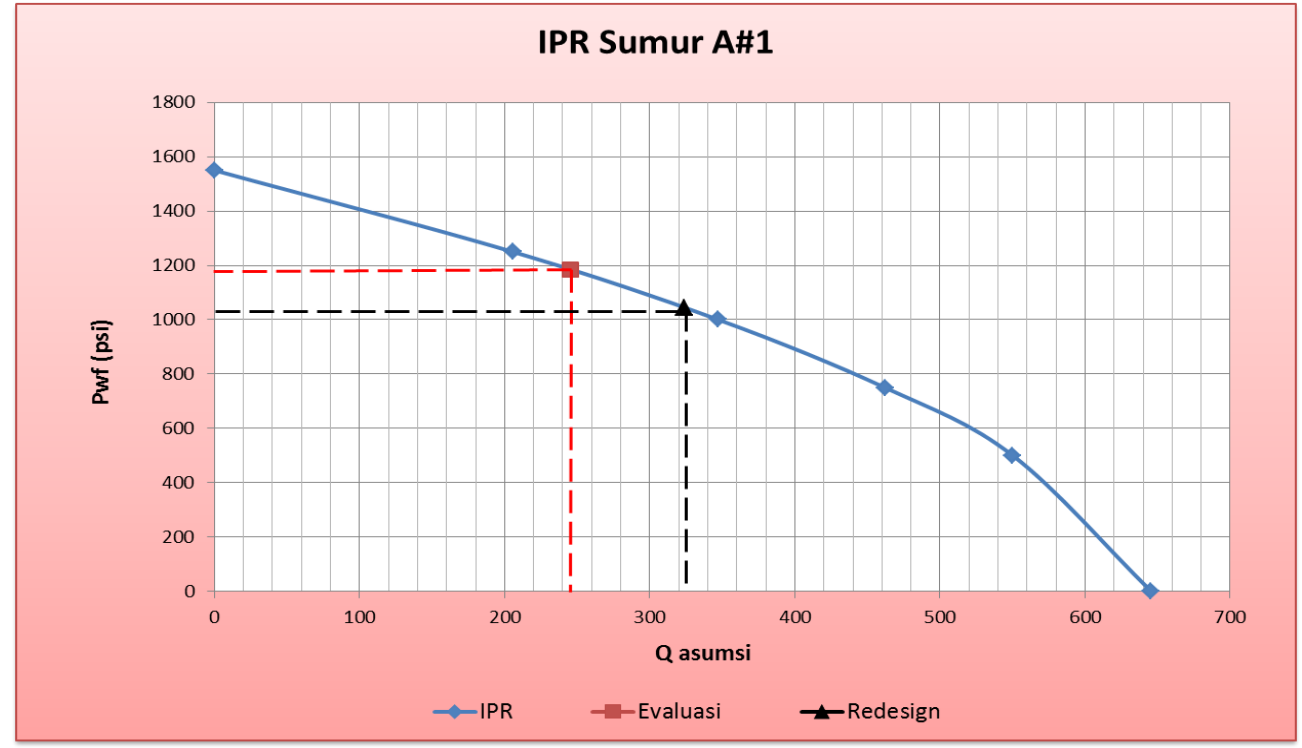

Gambar 4. IPR Sumur “A1” Setelah Redisign Manual

Berdasarkan optimasi produksi dengan Simulator Pipesim (current spacing) dapat mengubah katup operasi dari KSB III $(847.06 \mathrm{~m})$ menjadi KSB IV $(1062.23 \mathrm{~m})$. Kedalaman katupnya, yaitu $319.5 \mathrm{~m}, 601.81 \mathrm{~m}, 847.06 \mathrm{~m}$, $1062.23 \mathrm{~m}$, sedangkan tekanan buka katupnya, yaitu, 685.1 psi, 614.4 psi, 604.2 psi dan katup IV orifice. Laju produksi total yang dihasilkan lebih optimal dibandingkan sebelumnya. Laju produksi total yang diperoleh sebesar 335.3 bfpd pada Pwf 1022.1 psia sehingga produksi minyaknya sebesar 53.65 bopd (WC 84\%). Gambar 5. merupakan IPR setelah dioptimasi menggunakan current spacing.

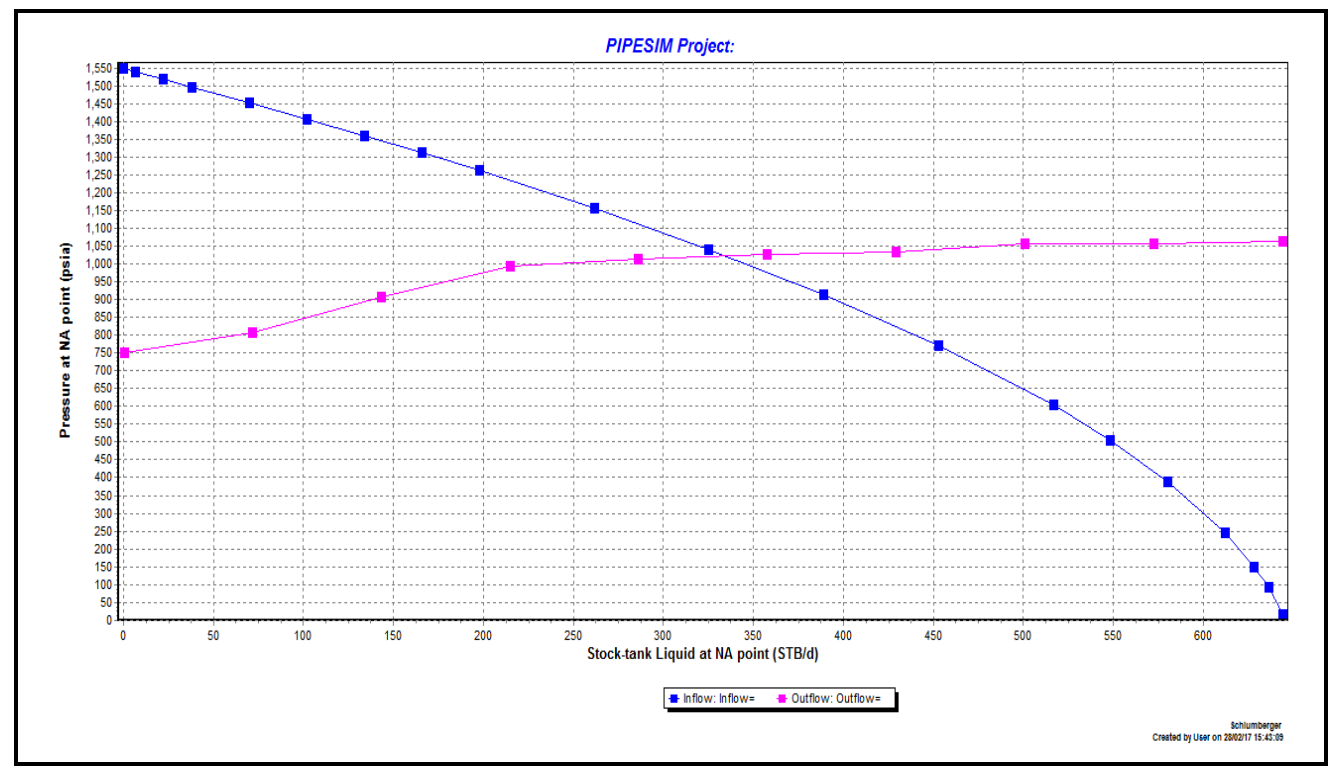

Gambar 5. IPR Setelah Optimasi Sumur “A1” Current Spacing

Berdasarkan perbandingan new spacing dan current spacing, hasil redesign dengan kedua metode tersebut cenderung sama. Namun, lebih efektif menggunakan current spacing karena tidak memerlukan rig untuk mengubah kedalaman katup existing sehingga dapat menghemat biaya, energi, dan waktu. Cukup hanya dengan menambah tekanan injeksi di permukaan dan laju injeksi gasnya, dapat diperoleh produksi yang lebih baik.

Dari hasil optimasi dapat dilihat bahwa laju produksi Sumur "A1" masih dapat ditingkatkan lagi, yaitu dari laju produksi 245 BFPD 
pada GLR $_{\text {Total }} 650.45 \mathrm{SCF} / \mathrm{STB}$ menjadi 335.3 BFPD pada GLR Total $_{2} 650$ SCF/STB. Sehingga diperoleh kenaikan produksi minyak dari 39.62 BOPD menjadi 53.65 BOPD. Kenaikan GLR Total setelah optimasi menunjukkan bahwa optimasi gas lift bergantung pada kenaikan laju alir gas injeksi dan tekanan injeksi permukaan. Sumur "A2" diproduksikan dari Formasi Jatibarang pada lapisan F dengan tenaga pendorong berupa solution gas drive. Optimasi Sumur "A2" menggunakan skenario yang sama dengan optimasi sumur "A1". Awalnya, dilakukan evaluasi dengan pipesim menggunakan single branch model. Input data pada Sumur "A2". Setelah running program modeling, dihasilkan IPR yang belum sesuai kondisi actual, maka dilakukan validasi model menggunakan flow correlation matching. Korelasi yang dipilih adalah korelasi Hagedorn \& Brown). Laju alir yang dihasilkan dari perpotongan kurva IPR dan TIP sebesar $62 \mathrm{STB} / \mathrm{d}$ pada tekanan alir dasar sumur sebesar 997.5 psia. Hasil ini yang paling mendekati kondisi aktual (Gambar 6). Kemudian, dilakukan desain existing continuous gas lift. Hasil evaluasinya, yaitu dengan laju alir gas injeksi 0,38 MMSCF/d dan tekanan injeksi permukaan 550 psia hanya mampu mengangkat cairan sampai pada katup ketiga (869.57 m) dengan laju alirnya sebesar 62 BFPD. Analisis IPR terdapat pada Gambar 6.

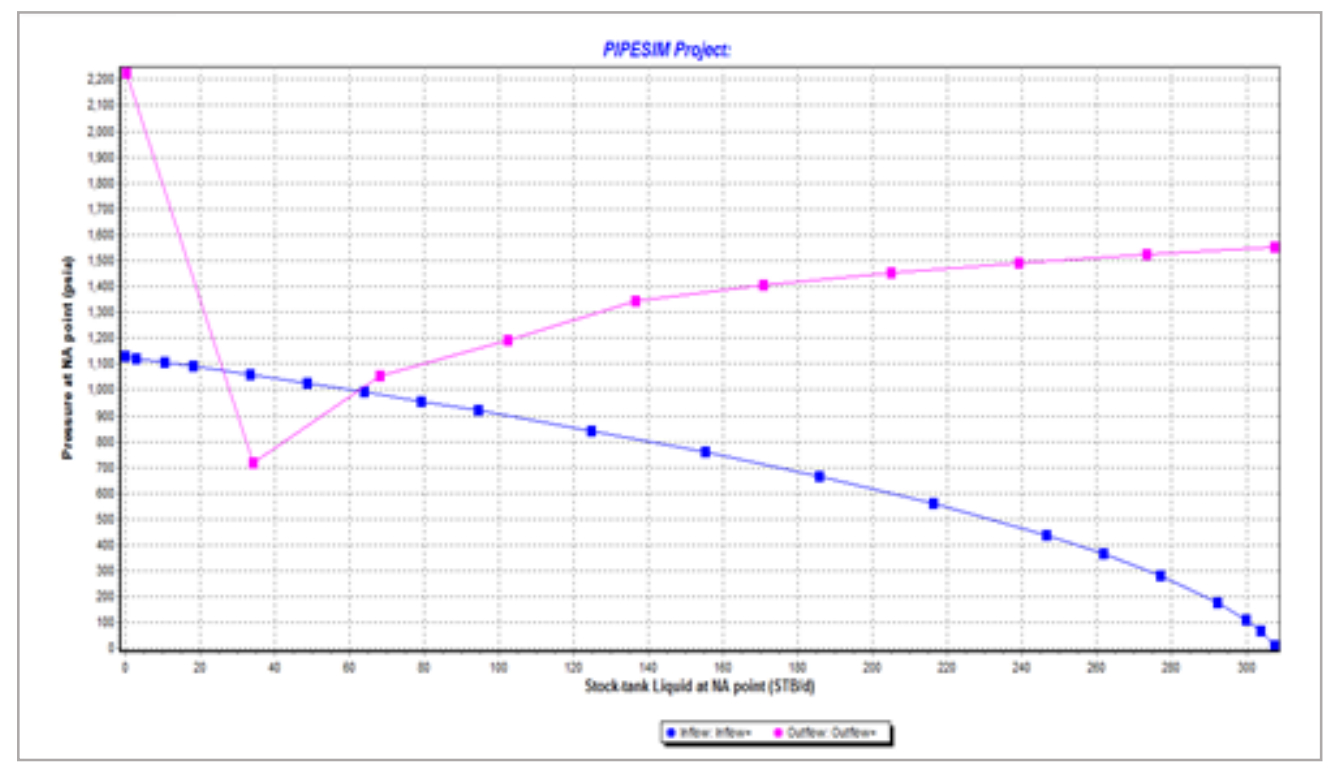

Gambar 6. Tampilan Validasi Model IPR dan TIP Sumur "A2"

Jika dilihat dari desain existing Continuous Gas Lift pada Sumur "A2", laju alir produksinya masih dapat ditingkatkan dengan menaikkan laju alir gas injeksi dan tekanan injeksi permukaannya berdasarkan kemampuan fasilitas di lapangan (Pso=750 psia dan Qgi=0.7 $\mathrm{mmscf} / \mathrm{d}$ ). Sehingga dilakukan redesign continuous gas lift dengan membandingkan metode simulator pipesim dan manual. Redesign menggunakan pipesim (new spacing) menghasilkan 6 katup, yaitu $465.12 \mathrm{~m}$, $803.67 \mathrm{~m}, 1045.8 \mathrm{~m}, 1204.3 \mathrm{~m}, 1301.1 \mathrm{~m}, 1356.5$ m. Sedangkan tekanan buka katupnya, yaitu 771.1 psi, 656.8 psi, 630.6 psi, 613.6 psi, 618.4 psi, dan KSB VI sebagai katup operasi (1356.5 m) dengan port size 5/16 inch. Laju produksi total sebesar 126 bfpd pada Pwf 840 psia sehingga memperoleh produksi minyak sebesar 32.65 bopd (WC 74\%). Gambar 7. merupakan tampilan IPR setelah redesign dengan new spacing.
Hasil redesign secara manual diperoleh katup VI sebagai katup operasi $(1386.77 \mathrm{~m})$ dengan laju produksi total 126 bfpd dan laju produksi minyak 32.65 bopd. Kedalaman katupkatupnya, yaitu $464.8 \mathrm{~m}, 777.2 \mathrm{~m}, 1013.4 \mathrm{~m}$, $1188.66 \mathrm{~m}, 1295.34 \mathrm{~m}, 1386.77 \mathrm{~m}$, sedangkan tekanan buka katupnya, yaitu 703.77 psi, 682.27 psi, 666.87 psi, 652.96 psi, 664.04 psi, dan KSB VI sebagai orifice. Gambar 8. merupakan IPR Sumur "A2" setelah redesign manual. Berdasarkan perbandingan keduanya, perbedaan terdapat pada kedalaman katup (Dv) dan tekanan buka katup (Ptro). Desain manual yang digunakan diasumsikan terjadi kesalahan pengamatan. Sehingga, penulis memilih menggunakan Pipesim new spacing untuk selanjutnya dibandingkan dengan optimasi Current Spacing. 




Gambar 7. Tampilan Grafis Redesign "New Spacing” Sumur “A2”

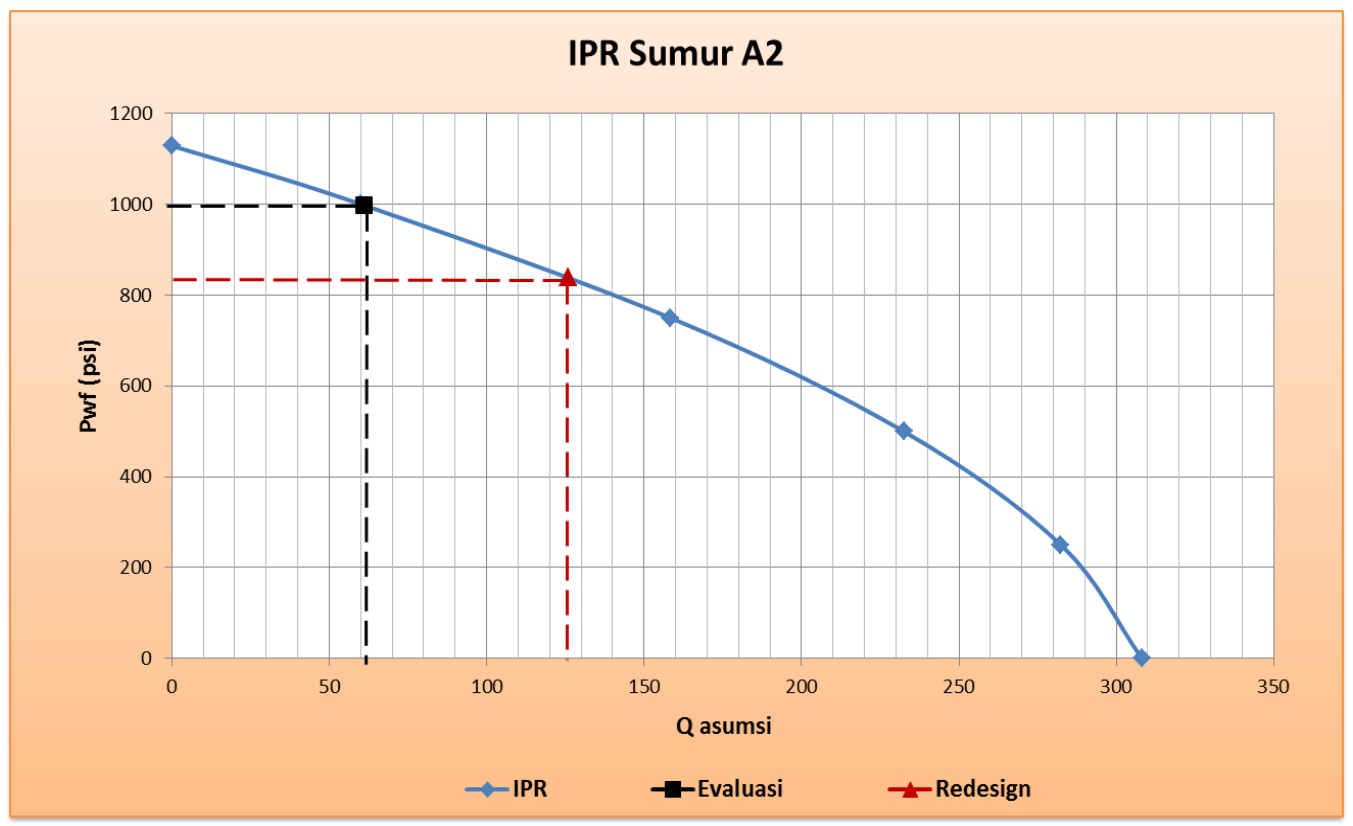

Gambar 8. IPR Sumur “A2” Setelah Redesign Manual

Berdasarkan optimasi produksi dengan Simulator Pipesim (current spacing) dapat mengubah katup operasi dari KSB III (847.06 m) menjadi KSB V (1365.3 m). Kedalaman katupnya, yaitu $328.59 \mathrm{~m}, 603.72 \mathrm{~m}, 869.52 \mathrm{~m}, 1118.74$, $1365.22 \mathrm{~m}$, sedangkan tekanan buka katupnya, yaitu 799.5 psi, 679 psi, 646.6 psi, 618.7 psi, dan KSB V sebagai orifice. Laju produksi total yang dihasilkan sebesar 128 bfpd (lebih optimal dibandingkan sebelumnya) pada Pwf 834 psia sehingga produksi minyaknya sebesar 33.28 bopd
(WC 74\%). Gambar 9. merupakan IPR setelah dioptimasi menggunakan currentspacing.

Berdasarkan perbandingan new spacing dan current spacing, hasil redesign dengan kedua metode lebih efektif menggunakan current spacing karena tidak memerlukan rig untuk mengubah kedalaman katup existing sehingga dapat menghemat biaya, energi, dan waktu. Cukup hanya dengan menambah tekanan injeksi di permukaan dan laju injeksi gasnya. 


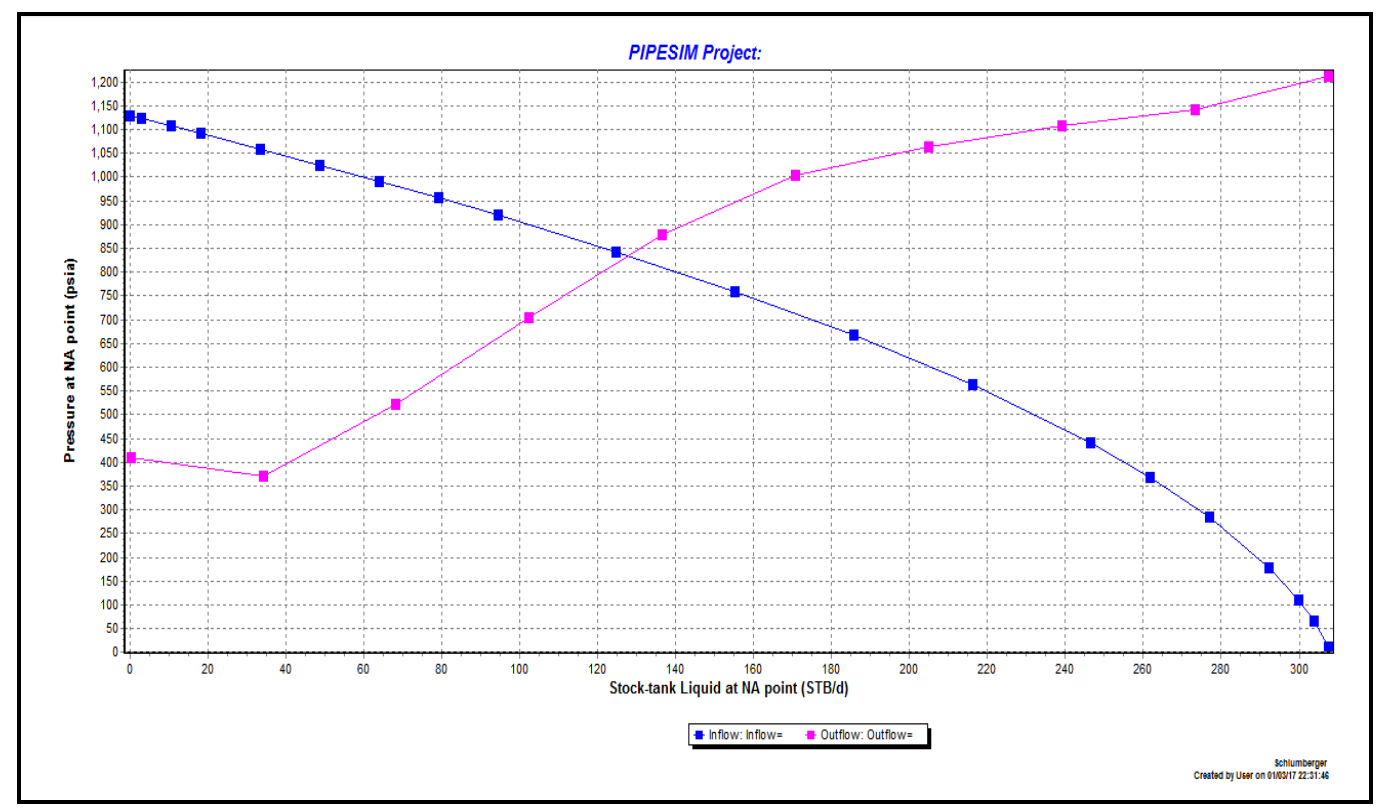

Gambar 9. IPR Setelah Optimasi Sumur “A2” Current Spacing

Dari hasil optimasi dapat dilihat bahwa laju produksi Sumur "A2" masih dapat ditingkatkan lagi, yaitu dari laju produksi 61 BFPD pada GLR $_{\text {Total }} 1311.47$ SCF/STB menjadi 128 BFPD pada GLR $_{\text {Total }} 6150 \mathrm{SCF} / \mathrm{STB}$ dengan kenaikan produksi minyak dari 15.86 BOPD menjadi 33.28 BOPD. Kenaikan GLR $_{\text {Total }}$ setelah optimasi ini menunjukkan bahwa optimasi gas lift bergantung pada kenaikan laju alir gas injeksi dan tekanan injeksi permukaan. Source Gas yang digunakan untuk menginjeksi sumur minyak adalah gas dari sumur-sumur produksi yang masuk ke jaringan. Untuk mempertahankan tekanan jaringan, perlu mengisi jaringan dengan sejumlah gas tertentu. Kemudian gas tersebut masuk ke kompresor untuk diinjeksikan ke sumur-sumur gas lift.Jika untuk mengoptimasi suatu sumur minyak butuh penambahan jumlah gas injeksi, artinya jumlah gas yang di jaringan akan berkurang dan akibatnya tekanan jaringan juga akan berkurang.

Studi perbandingan perencanaan optimasi produksi continuous gas lift dalam penelitian ini dilakukan perhitungan hanya dari segi keteknikan dan belum menyertakan perhitungan dari segi ekonomi.

\section{Kesimpulan}

Berdasarkan evaluasi, redesign dan optimasi continuous gas lift dengan simulator pipesim dan manual untuk meningkatkan profil produksi dari sumur "A1" dan "A2" pada lapangan "D" dapat disimpulkan bahwa:
1. Laju gas injeksi dan tekanan injeksi untuk mengoptimasi sumur "A1" dan "A2" disesuaikan dengan fasilitas permukaan dan sumber gas yang tersedia adalah 0,7 MMSCF/d dan 750 psia.

2. Existing design pada sumur "A1" menggunakan Continuous Gas Lift dengan titik injeksi di kedalaman $1122.2 \mathrm{~m}$, tekanan injeksi 550.7 psia, GLRtotal 650.45 SCF/STB, laju injeksi gas 0.4 MMSCF/d, laju produksi total 245 BFPD, dan laju produksi minyak 39.2 BOPD (WC 84\%).

3. Redesign menggunakan pipesim (new spacing) menghasilkan 5 katup yaitu 459.73 m, 745.48, 935.37, 1055.7, $1122.2 \mathrm{~m}$. Sedangkan tekanan buka katupnya, yaitu 666.4 psi, 613.3 psi, 604.3 psi, 610.3 psi, dan KSB V sebagai katup operasi (1122.2 m) dengan port size 5/16 inch.

4. Perbandingan redesign dengan simulator pipesim "new spacing" dan desain manual, hasilnya cenderung sama. Sehingga digunakan "new spacing" yang dinilai lebih teliti dengan titik injeksi di kedalaman $1122.2 \mathrm{~m}$, GLRtotal $2650 \mathrm{SCF} / \mathrm{STB}$, laju produksi total $324 \mathrm{BFPD}$, dan laju produksi minyak 51.84 BOPD (WC $84 \%)$.

5. Pertimbangan optimasi sumur "A1" juga dilakukan menggunakan "current spacing" sebagai pembanding redesign new spacing dengan titik injeksi di kedalaman $1062.23 \mathrm{~m}$, GLRtotal $2650 \mathrm{SCF} / \mathrm{STB}$, laju produksi total 335.3 BFPD, dan laju produksi minyak 53.65 BOPD (WC 84\%). Kedalaman katupnya, yaitu 


\section{ANALISA PERBANDINGAN PERENCANAAN OPTIMASI CONTINUOUS GAS LIFT DENGAN SIMULATOR PIPESIM DAN MANUAL SUMUR "A1" DAN "A2" DI LAPANGAN "D"}

$319.5 \mathrm{~m}, 601.81 \mathrm{~m}, 847.06 \mathrm{~m}, 1062.23 \mathrm{~m}$, sedangkan tekanan buka katupnya, yaitu, 685.1 psi, 614.4 psi, 604.2 psi dan katup IV orifice.

6. Peningkatan fluida yang dihasilkan pada Sumur "A1", yaitu dari 245 BFPD menjadi 324 BFPD dengan kenaikan perolehan minyak dari 39.2 BOPD menjadi 53.65 BOPD.

7. Berdasarkan data existing design, sumur "A2" menggunakan Continuous Gas Lift dengan titik injeksi di kedalaman $869.57 \mathrm{~m}$, tekanan injeksi 550 psi, GLRtotal 1311.47 SCF/STB, laju injeksi gas $0.38 \mathrm{MMSCF} / \mathrm{d}$, laju produksi total 61 BFPD, dan laju produksi minyak 15 BOPD (WC 74\%).

8. Redesign menggunakan pipesim (new spacing) pada sumur "A2" menghasilkan 6 katup, yaitu $465.12 \mathrm{~m}, 803.67 \mathrm{~m}, 1045.8 \mathrm{~m}, 1204.3 \mathrm{~m}$, $1301.1 \mathrm{~m}, 1356.5 \mathrm{~m}$. Sedangkan tekanan buka katupnya, yaitu 771.1 psi, 656.8 psi, 630.6 psi, 613.6 psi, 618.4 psi, dan KSB VI sebagai katup operasi (1356.5 m) dengan port size 5/16 inch.

9. Perbandingan redesign dengan simulator pipesim "new spacing" serta desain manual, hasilnya cenderung sama. Sehingga digunakan "new spacing" yang dinilai lebih teliti dengan titik injeksi di kedalaman $1356.5 \mathrm{~m}$, GLRtotal $5700 \mathrm{SCF} / \mathrm{STB}$, laju produksi total $126 \mathrm{BFPD}$, dan laju produksi minyak 32.65 BOPD (WC $74 \%)$.

10. Pertimbangan optimasi sumur "A2" juga dilakukan menggunakan "current spacing" dengan titik injeksi (1365.3 m), GLRtotal 5700 SCF/STB, laju produksi total 128 BFPD, dan laju produksi minyak 33.28 BOPD (WC 74\%). Kedalaman katupnya, yaitu 328.59 m, 603.72 $\mathrm{m}, 869.52 \mathrm{~m}, 1118.74,1365.22 \mathrm{~m}$, sedangkan tekanan buka katupnya, yaitu 799.5 psi, 679 psi, 646.6 psi, 618.7 psi, dan KSB V sebagai orifice.

11. Peningkatan fluida yang dihasilkan pada Sumur "A2", yaitu dari 61 BFPD menjadi 128 BFPD dengan kenaikan perolehan minyak dari 15 BOPD menjadi 33.28 BOPD.

12. Pada sumur "A1" dan "A2" lebih efektif mengoptimasi produksi berdasarkan current spacing karena tidak memerlukan rig untuk mengubah kedalaman katup existing sehingga dapat menghemat biaya, energi, dan waktu. Cukup hanya dengan menambah tekanan injeksi di permukaan dan laju injeksi gasnya, dapat diperoleh produksi yang lebih baik.

13. Source Gas yang digunakan untuk menginjeksi sumur "A1" dan "A2" adalah gas dari sumursumur produksi yang masuk ke jaringan. Untuk mempertahankan tekanan jaringan, perlu mengisi jaringan dengan sejumlah gas tertentu. Kemudian gas tersebut masuk ke kompresor untuk diinjeksikan ke sumur-sumur gas lift.

\section{Daftar Pustaka}

Abdassah, Doddy., “Teknik Gas Bumi”, Jurusan Teknik Perminyakan, Institut Teknologi Bandung, 1998.

Amyx, J.W., Bass, Jr D.M., Whitting, R.L., "Petroleum Reservoir Engineering Physical Properties", First Edition, McGraw-Hill Book Company, Inc., New York, 1960.

Brown, K.E., Beggs, H.D., "The Technology of Artificial Lift Methods", Volume 1, PennWell Publishing Company, Tulsa, Oklahoma, 1977.

Brown, K.E., "The Technology of Artificial Lift Methods", Volume 2A, PennWell Publishing Company, Tulsa, Oklahoma, 1980.

Brown, K.E., "The Technology of Artificial Lift Methods", Volume 4, PennWell Publishing Company, Tulsa, Oklahoma, 1984.

Dewi, Aristanti O., "Seminar Evaluasi dan Optimasi Produksi Menggunakan Metode Continuous Gas Lift", Universitas Proklamasi 45, Yogyakarta, 2016.

Hariyadi, dkk., "Pengantar Teknik Perminyakan (TM-110)", Universitas Pembangunan Nasional "Veteran", Yogyakarta, 2004.

Latuan, Yosef B. B., "Perencanaan Optimasi Produksi Continuous Gas Lift Pada Sumur "X" Lapangan "Y" PT. Pertamina EP Asset 2 Menggunakan Simulator Pipesim", UPN "V", Yogyakarta, 2016.

Mandala, Wirawan W., "Mekanika Reservoir", Gallery Ilmu, Yogyakarta, 2014. 6

Mandala, Wirawan W., "Metode Pengangkatan Buatan (Gas Lift)", -, Yogyakarta, -.

Nind, T.E.W., "Principle of Oil Well Production", McGraw-Hill Book, Company, Inc., New York, 1964.

Pettijhon. S.J., "Sedimentary Rock", Oxford and IBH Publishing Co., New York, 1957. 9

PT. Pertamina EP, "Profil PT. Pertamina EP", 2017.

PT. Pertamina EP Asset 3, "Data Sumur CMB-14, $C M B-26, \quad C M B-13, \quad C M B-15$ Jatibarang Field", Cirebon, 2017. 
Jurnal OFFSHORE, Volume 1 No. 2 Desember 2017 : 22 - 32 ; e -ISSN : 2549-8681

PT. Pertamina EP Asset 3, "Profil dan Tinjauan Lapangan PT. Pertamina EP Asset 3 Jatibarang Field", Cirebon, 2017.

Purwaka, Edi., "Gas Lift", Universitas Proklamasi 45, Yogyakarta, 2011.

Rukmana, D., Kristanto, D., “Teknik Reservoir : Teori dan Aplikasi”, Pohon Cahaya, Yogyakarta, 2012.
Schlumberger, "Gas Lift Design and Performance", Simulator Pipesim, 2008.

"Gas Lift Book 6 of The Vocational Training Series”, Third Edition, API, Dallas, 1994. 